\title{
INVENTÁRIO LEXICAL \\ DO PORTUGUÊS FALADO \\ NA REGIÃO NORTE \\ DO BRASIL: ESTUDO \\ LEXICOGRÁFICO COM \\ BASE NOS DADOS \\ DO PROJETO ALIB
}

\section{INVENTARIO LÉXICO DEL PORTUGUÉS HABLADO EN EL NORTE DE BRASIL: ESTUDIO LEXICOGRÁFICO BASADO EN DATOS DEL PROYECTO ALIB}

\section{LEXICAL INVENTORY OF PORTUGUESE SPOKEN IN NORTH OF BRAZIL: LEXICOGRAPHIC STUDY BASED ON ALIB DATA}

Cemary Correia de Sousa*

Universidade Federal da Bahia

RESUMO: O presente trabalho buscou investigar de que maneira os contatos linguísticos e culturais com outros povos contribuíram para a formação do léxico do português brasileiro. Para tal, o corpus foi constituído a partir das diferentes denominações dadas como respostas pelos informantes a questões do Questionário Semântico-Lexical (QSL), instrumento metodológico utilizado pelo Projeto Atlas Linguístico do Brasil (ALiB), como a proposição: "Durante uma chuva podem cair bolinhas de gelo. Como chamam essa chuva?". Para além da presença de elementos latinos, peculiares às línguas românicas, observam-se unidades lexicais no português afluentes de elementos autóctones, africanos e das línguas de imigração. Assim, propõese, neste artigo, uma análise, ainda que breve, das línguas que ajudaram na formação do magno edifício lexical do português brasileiro, com base nos pressupostos da Lexicografia variacional, para que assim se possa "amarrar" as narrativas históricas que compõem a história interna e externa do português brasileiro, em sua nuance vernácula.

PALAVRAS-CHAVE: Léxico. Lexicografia. Projeto ALiB. Contatos linguísticos.

RESUMEN: El presente trabajo buscó investigar cómo los contactos lingüísticos y culturales con otros pueblos contribuyeron a la formación del léxico del portugués brasileño. Para eso, el corpus se constituyó a partir de los diferentes nombres dados, como 
respuestas por los informantes, a las preguntas del Cuestionario Semántico Léxico (QSL), un instrumento metodológico utilizado por el Projeto Atlas Linguístico do Brasil (ALiB), como la proposición: "Durante una lluvia pueden caer bolas de hielo. ¿Cómo llamas a esta lluvia? Además de la presencia de elementos latinos, peculiares de las lenguas romances, existen unidades léxicas en portugués que son afluentes de elementos indígenas, africanos y las lenguas de inmigración. Por lo tanto, este artículo propone un breve análisis de las lenguas que ayudaron a la formación del magnífico edificio léxico del portugués brasileño, basado en los supuestos de la lexicografía variacional, con miras a unir las narrativas históricas que componen la historia interna y externa del portugués brasileño en su matiz vernáculo.

PALABRAS CLAVE: Léxico. Lexicografía. Proyecto ALiB. Contactos lingüísticos.

ABSTRACT: The present work sought to investigate how linguistic and cultural contacts with other peoples contributed to the formation of the lexicon of Brazilian Portuguese. For this, the corpus was constituted from the different names given as answers by the informants to questions of the Semantic Lexical Questionnaire (QSL), a methodological instrument used by the Linguistic Atlas Project of Brazil (ALiB), as the proposition: “During a rain, little ice balls may fall. What do you call this rain?". In addition to the presence of Latin elements, peculiar to the Romance languages, there are lexical units in Portuguese affluent with indigenous elements, African and the languages of immigration. Thus, this article proposes a brief analysis of the languages that helped in the formation of the magnificent lexical building of Brazilian Portuguese, based on the assumptions of the variational lexicography, so that the historical narratives that make up the internal and external history of Brazilian Portuguese, in its vernacular nuance, can be tied.

KEYWORDS: Lexicon. Lexicography. ALiB Project. Language contacts.

\section{CONSIDERAÇÕES INICIAIS}

Ao contrário do que possam decretar certos falantes ou gramáticos, a realidade multifacetada do português brasileiro não denota caos, deturpação ou risco de morte da língua. De tal modo, em consonância com o desenvolvimento dos estudos linguísticos, podese atestar que a variação linguística é inerente a qualquer língua humana e pode ser observada sincronicamente, através da diversidade dialetal, ou diacronicamente, por processos de mudança linguística.

Assim, a língua é entendida como um produto social e cultural, sujeita a variações e mudanças, contrariando a antiga ideia de que seria uma realidade unitária e homogênea. Compreende-se, sob esse viés, que a língua, por representar a cultura e história de um povo, não pode ser melhor analisada, senão pela sua realização real em contexto de interação. Conforme aponta Faraco (2016, p. 9):

[...] as línguas estão intimamente atadas às dinâmicas histórico-políticas e às construções imaginário-ideológicas das sociedades em que são faladas. Em outros termos, as línguas não existem em si e por si; elas não são entidades autônomas - as línguas são elas e seus falantes; elas e as sociedades que as falam.

Concordando com tal assertiva, dentre os diversos níveis da língua, observa-se que o léxico, por ser o nível linguístico que mais sofre modificações "[...] sociais e culturais que acarretam alterações nos usos vocabulares" (BIDERMAN, 2001, p. 39), revela marcas do ambiente físico e social em que o indivíduo está inserido.

Em face disso, a sua dinamicidade permite não só a alteração da carga semântica ao longo do tempo histórico, mas a criação de novas unidades e (ou) desuso de outras, atitudes que, obviamente, convergem com as necessidades de comunicação dos falantes.

Dessa forma, as mudanças no âmbito do léxico são influenciadas não apenas por condicionantes linguísticos, mas também (e principalmente) por fatores extralinguísticos, como os contatos interétnicos e contingências socioeconômicas e geográficas, por exemplo, provocando o surgimento de distintas normas lexicais em uso pelos grupos sociais.

O léxico, entretanto, até recentemente tinha ocupado um lugar secundário em relação ao estudo de outros níveis da língua, como a morfossintaxe. Não obstante, esse cenário: 
[...] depois de longo tempo do que se poderia chamar de obscureza científica, passou, nos últimos anos, essa entidade teórica ou, como preferem alguns chamar, nível de análise, a ser considerada pela linguística contemporânea - ao menos para alguns pesquisadores -, como "elemento central da língua" (VILELA, 1979, p. 17), tirando da sintaxe a hegemonia dos estudos linguísticos. (MACHADO FILHO, 2010, p. 49).

No tocante a essa questão, ao se observarem as pesquisas dialetais já publicadas ou em andamento, torna-se imprescindível a referência a um dos maiores projetos de cunho dialetal e sociolinguístico vigentes no Brasil, o Projeto Atlas Linguístico do Brasil ALiB.

A ideia inaugural de elaboração de um atlas linguístico do Brasil no que se refere à língua portuguesa surge com o decreto 30.643 , de 20 de março de 1952, conforme exposto em seu parágrafo $3^{\circ}$ :

$\$ 30$ - A Comissão de Filologia promoverá pesquisas em todo o vasto campo de filologia portuguesa fonológicas, morfológicas, sintáticas, léxicas, etimológicas, métricas, onomatológicas, dialetológicas bibliográficas, históricas, literárias, problemas de texto, de fontes, de autoria, de influências, sendo sua finalidade principal a elaboração do "Atlas Linguístico do Brasil”. (BRASIL, 1952, p. 170)

Contudo, por fatores de diversa ordem, sobretudo, política, a ideia de um atlas nacional foi postergada, levando-se a pensar na produção de atlas regionais, enquanto não se atingia o objetivo primeiro. Dentre eles, merece lugar de destaque o Atlas Prévio dos Falares Baianos (APFB), fruto do trabalho pioneiro de Nelson Rossi e de sua equipe, financiado pela Universidade Federal da Bahia e publicado em 1963, angariando o título de primeiro atlas linguístico do país. Acerca da literatura sobre o tema já produzida, Razky e Sanches $(2015$, p. 2) destacam que:

Os principais trabalhos e estudos de natureza dialetal no Brasil são descritos por Ferreira e Cardoso (1994), em três grandes fases. A primeira vai de 1826 até 1920, data de publicação de O dialeto caipira de Amadeu Amaral. Os trabalhos de Amaral são caracterizados como estudos voltados para o léxico, do qual, resultaram numerosos dicionários. A segunda inicia-se a partir da publicação de O dialeto caipira (1920). O conhecimento empírico da realidade linguística e a ausência de trabalho de campo sistemático, que marcaram a primeira fase, permanecem nesta segunda, porém, agora se tem uma maior preocupação com a metodologia utilizada nos estudos dialetológicos. Destacam-se aqui dois trabalhos, o referenciado na primeira fase, O dialeto caipira e O linguajar carioca em 1922 de Antenor Nascentes. O marco da terceira fase data do ano de 1952 com o decreto 30.643 de 20 de março de 1952 que previa a elaboração do Atlas Linguístico do Brasil .

Para os pesquisadores mencionados, $\mathrm{o}$ :

ALiB é um dos projetos macros de dialetologia e sociolinguística que nasce em meio as discussões anteriores e das pesquisas já realizadas [...]. O momento mais importante e que deu impulso para a construção do ALiB foi o Seminário Caminhos e Perspectivas para a Geolinguística no Brasil realizado na Universidade Federal da Bahia em 1996. Conforme Cardoso (2009), esse espaço foi favorável à construção do projeto, pois reuniu pesquisadores no campo da dialetologia e da sociolinguística, contando com a presença dos autores de atlas linguísticos já publicados, até àquela época. (RAZKY; SANCHES, 2015, p. 2)

O Projeto ALiB tem, pois, por objetivo "[...] descrever a realidade linguística do Brasil, no que tange à língua portuguesa, com enfoque prioritário na identificação das diferenças diatópicas (fônicas, morfossintáticas, léxico-semânticas e prosódicas) consideradas na perspectiva da geolinguística" (CARDOSO, 2010, p. 169). Para tal empreitada, o projeto mapeou 250 localidades desde o Oiapoque até o Chuí ${ }^{1}$, englobando as capitais e cidades do interior, com vistas a divulgar a riqueza da diversidade linguística no país.

${ }^{1} \mathrm{O}$ município de Oiapoque está localizado no extremo norte do estado do Amapá e o Chuí localiza-se no extremo sul do Brasil. 
Partindo dessas observações iniciais, este estudo traz à cena o léxico do português brasileiro no tocante à Região Norte do Brasil, já que são poucos os trabalhos de cunho lexicográfico que versam sobre a norma lexical da Região. Para tal, são percorridos os caminhos das capitais, a partir dos inquéritos realizados pelo Projeto ALiB em 6 localidades investigadas, a saber: Belém, Boa Vista, Macapá, Manaus, Porto Velho e Rio Branco.

Desse modo, este estudo oferece o registro de dados lexicais tratados sob a égide da Lexicografia variacional em interface com a dialetologia. Outrossim, em algum grau, tenta-se preencher, mesmo parcialmente, a lacuna existente no que concerne a obras lexicográficas que forneçam dados científicos - tratados sob princípios teóricos consistentes - para além de contribuir com a salvaguarda do "magno edifício" lexical do português, a que se refere Piel (1991, p. 235) -, isto é, para a composição histórica do léxico de língua, em que os diferentes falares nacionais possam, enfim, se evidenciar.

\section{BREVE HISTÓRIA DA LÍNGUA PORTUGUESA NOS PRIMEIROS ANOS DE TERRA BRASILIS}

Refletir acerca do processo de povoamento e mobilidade demográfica da Região Norte demanda, a priori, evocar como centro da discussão a ideia das diásporas que marca os territórios e as formas como os grupos sociais se reorganizaram nesses novos espaços. Assim, os deslocamentos e as relações estabelecidas com o novo território são constitutivos de significados culturais, ao invés de serem uma simples extensão e transferência do lugar de origem.

Embora se possa asseverar que "[...] mesmo os membros da mais minúscula nação jamais conhecerão, encontrarão, ou sequer ouvirão falar da maioria de seus companheiros", devem ter, entretanto, todos "em mente a imagem viva da comunhão entre eles" (ANDERSON, 2008, p. 32). Entende-se, nesse sentido, que remontar os caminhos da história no que tange aos dados cronológicos e socioculturais é lidar com o processo de formação da nação brasileira, e, em paralelo, traçar os caminhos para a adoção e difusão da língua portuguesa no extenso e plural território nacional. Isso se pode perceber melhor se revermos o cenário de conformação linguística do Brasil desde a colonização até os dias atuais.

Ao estudar a sócio-história do português brasileiro, observa-se que a língua do europeu começa a ser transplantada para o Brasil no século XVI, juntamente com a empresa exploratória. Porém, devido ao cenário de multilinguismo generalizado característico do Brasil-Colônia, a língua só passa a ser majoritária e oficial em meados do século XVIII. A esse respeito, de acordo com Mattos e Silva (2004, p. 20-21):

Em 1757, com o Marquês de Pombal, se define explicitamente para o Brasil uma política linguística e cultural que fez mudar de rumo a trajetória que poderia ter levado o Brasil a ser uma nação de língua majoritária indígena, já que os dados históricos informam que uma língua geral de base indígena ultrapassara de muito as reduções jesuíticas e se estabelecia como língua familiar no Brasil eminentemente rural de então. Pombal define o português como língua de colônia, consequentemente obriga o seu uso na documentação oficial e implementa o ensino leigo no Brasil, antes restrito à Companhia de Jesus, que foi expulsa do Brasil.

No contexto desse esboço histórico, acabou por prevalecer no país o ideal homogeneizador do português, que procurou apagar, progressivamente, toda e qualquer "marca" das línguas autóctones e africanas, desaguando na alegada "vitória da língua portuguesa”, tão propalada por Serafim da Silva Neto:

Por causa, precisamente, dessa falta de prestígio é que a linguagem adulterada dos negros e índios não se impôs senão transitoriamente: todos os que puderam adquirir uma cultura escolar e que, por esse motivo, possuíam o prestígio da literatura e da tradição, reagiram contra ela. (SILVA NETO, 1960, apud MATTOS E SILVA, 2004)

Esse ideal não sofreu o êxito esperado. Desse quadro geral, infere-se que o português trazido pelos homens do aquém-mar começa a ganhar novos contornos por conta dos diferentes povos e culturas com os quais esteve em contato. De tal forma, emerge uma 
língua que se distancia da matriz e agrega na sua constituição a diversidade, fomentando a construção das suas variedades sociais, dentro de uma perspectiva plural e polarizada, conforme proposição de Lucchesi (2004).

Dessarte, há uma articulação entre as normas populares, cultivadas e espraiadas pela massa populacional, e as normas cultas, dominadas por uma ínfima parte da sociedade brasileira com acesso ao ensino escolar e aos bens culturais. De tal modo, no esteio dos trânsitos culturais, esses polos se encontram e interagem de forma contínua. A situação apresentada pode ser resumida no seguinte excerto retirado de Lucchesi (2009, p. 41):

No Brasil, o contato dos colonizadores portugueses com milhões de aloglotas, falantes de mais de mil línguas indígenas autóctones e de cerca de duzentas línguas que vieram na boca de cerca de quatro milhões de africanos trazidos para o país como escravos, é, sem sombra de dúvida, o principal parâmetro histórico para a contextualização das mudanças linguísticas que afetaram o português brasileiro.

A partir daí, evidencia-se a complexa situação de contato entre as línguas que compõem a história linguística do português brasileiro, sobretudo no que tange ao extermínio das línguas indígenas e de seus povos.

Recuperando um pouco mais detalhadamente esse cenário, vê-se que foi o século XVI o ano da expansão europeia, da conquista e domínio do Novo Mundo. Tal período é marcado pelo deslumbramento com as novas terras e o encontro com o "outro", processo intrinsecamente caracterizado por violências e humilhações, levando ao extermínio/apagamento do mais fraco, na maioria das vezes. Nesse contexto, destaca-se ainda o início da colonização do território brasileiro, composto por singularidades no que tange à colonização de outras partes do continente americano, sobretudo de natureza linguística.

Nos anos iniciais da colonização, o desenvolvimento de duas línguas gerais indígenas como "línguas de grande difusão numa área", ainda que tal definição não seja consenso entre os pesquisadores da área, foi fundamental para que os portugueses pudessem impulsionar a empresa exploratória ao utilizá-las como veículo de comunicação. Nesse esteio, houve o desenvolvimento da Língua Geral Paulista (LGP) e da Língua Geral Amazônica (LGA).

O surgimento da LGP está diretamente relacionado à fundação da Capitania de São Vicente, em 1532, e a seu posterior povoamento. Com o estabelecimento da Capitania em solo tupi, cresceu consideravelmente a interação dos portugueses com esses índios, não só do litoral, mas, também e, sobretudo, no planalto da Tabatinga e ao longo do rio Tietê. Com o afluxo de homens portugueses ao novo território, passaram eles a viver com as mulheres indígenas. Assim:

Esta foi a situação que prevaleceu na Capitania de São Vicente junto aos tupí [sic]. Como em geral, para cada filho de português com mulher tupí [sic] não havia outros parentes portugueses, mas somente os parentes indígenas da família da mãe, os mamelucos se tornaram falantes da língua materna, a língua dos tupí [sic]. Logo, porém, esses mamelucos passaram a seguir as atividades de seus pais, distanciando-se social e culturalmente das sociedades indígenas de que provinham suas mães. (RODRIGUES, 2006, p. 148)

Como aponta Rodrigues (2006), de meados do século XVI até a primeira metade do século XVIII, a língua geral paulista tornou-se o idioma da Capitania de São Vicente, de onde foi levada pelos bandeirantes, muitos dos quais eram mamelucos, para os territórios de Minas Gerais, Goiás e Mato Grosso.

Por outro lado, desde o século XVII a LGA acompanhou a expansão portuguesa no norte do território, sendo levada pelos missionários, soldados e colonos e lá prevaleceu até o século XIX², sendo a língua dos brasileiros e colonizadores. De tal forma, os sujeitos falantes de outras línguas, incorporados ao sistema colonial, como índios de missões e escravos, "aprendiam neste contato forçado a falar a LGA e aumentavam o número dos que usavam essa língua como segunda ou primeira língua” (RODRIGUES, 2006, p. 149).

${ }^{2}$ Observe-se que a derrocada da língua geral, como um todo, inicia-se com as políticas pombalinas em meados do século XVIII. 
Apesar de todos os esforços empreendidos pelo Marquês de Pombal em meados do século XVIII para extinguir as línguas gerais em prol da valorização e disseminação da língua portuguesa, foi a LGA a língua do povo em toda a Província do Amazonas e em boa parte do Pará, até a segunda metade do século XIX, já que houve uma dizimação acentuada da população que mantinha tal língua em uso. Concorda-se, a esse propósito, com o que afirma Rodrigues (2006, pp. 149-150):

Em consequência da população ocorrida, quando, no final do século tratou-se de intensificar a extração da borracha, foi necessário importar maciçamente mão-de-obra de fora da Amazônia, particularmente dos estados nordestinos, nos quais a única língua popular era o português. Foi então que esta língua passou a ter seu curso geral em porções cada vez extensas da Amazônia. O ciclo econômico da borracha, além de renovar a população, contribuiu para o desenvolvimento do comércio e da navegação, reforçando a implantação do português. No início do século XX, o uso da LGA foi ficando limitado a algumas ilhas populacionais nos rios Tapajós, Madeira e Solimões, mas com um grande reduto no alto rio Negro e em seus afluentes, principalmente no Içana e no Uaupés.

A respeito do delineamento desse cenário, ainda que breve, torna-se evidente que o encontro entre o português e as cerca de 1200 línguas indígenas presentes na costa no momento da colonização do Brasil foi marcado por uma história de glotocídios e extermínio de populações inteiras. Afora isso, as distintas ondas migratórias, as quais foram proporcionadas pelos diferentes ciclos econômicos, ajudariam a montar o cenário linguístico da Região Norte. Entende-se, assim, que a formação da língua portuguesa no Brasil está diretamente relacionada ao desenvolvimento histórico do país e suas particularidades.

\section{DIALETOLOGIA E LEXICOGRAFIA: UM DIÁLOGO INTERDISCIPLINAR}

Cardoso (2008, p. 16) define a dialetologia como "[...] ramo dos estudos da ciência da linguagem que se ocupa da variação e da diversidade de usos". Desde o surgimento dos primeiros trabalhos na área da dialetologia, em meados do século XIX, coube a ela a função de registrar e fornecer tratamento adequado à variação lexical independente das ocorrências encontradas fazerem ou não parte do standard linguístico. Para tal, utiliza-se como metodologia de trabalho a geolinguística ou geografia linguística, a qual o seu surgimento:

[...] como disciplina autônoma está associado à elaboração do ‘Atlas linguistique de la France’ (ALF) (1902-1910) de J, Gilliéron e E. Edmont, que embora surja na seqüência de outros trabalhos desta natureza, é o primeiro atlas lingǘstico a orientar-se pelos critérios mais rigorosos que esta disciplina veio a optar. A Geografia Lingüística é, desde então, entendida como o estudo cartográfico dos dialetos. (FERREIRA, 1996, p. 484)

Com o aperfeiçoamento do método geolinguístico, mais precisamente com o estabelecimento da concepção pluridimensional dos estudos dialetológicos, a partir da segunda metade do século XX, foi possível registrar os usos linguísticos em distintas e diversificadas partes do país e considerar, também, os aspectos sociológicos que, em algum grau, condicionam o comportamento linguístico do falante. A esse respeito, Cardoso (2010, p. 25) considera que:

[...] estudando a língua, instrumento responsável pelas relações sociais que se documentam entre membros de uma coletividade ou entre povos, a dialetologia não pôde deixar passar ao largo a consideração de fatores extralinguísticos, inerentes aos falantes, nem relegar o reconhecimento de suas implicações nos atos de fala. Dessa forma, idade, gênero, escolaridade e características gerais de cunho sociocultural dos usuários das línguas consideradas tornam-se elementos de investigação, convivendo com a busca de identificação de áreas geograficamente definidas do ponto de vista dialetal.

A partir do momento em que os dialetos se tornam objeto de atenção dos linguistas, tem-se, então, o dialeto como objeto de estudo dessa disciplina. Tal conceito é abordado de diferentes maneiras de acordo com a concepção adotada por cada linguista. No dizer do linguista romeno Eugenio Coseriu (1982, p. 11-12): 
[...] um dialeto, sem deixar de ser intrinsecamente uma língua, se considera subordinado a outra língua, de ordem superior. Ou, dizendo de outra maneira: o termo dialeto, enquanto oposto à língua, designa uma língua menor incluída em uma língua maior, que é justamente, uma língua histórica (ou idioma). Uma língua histórica - salvo casos especiais - não é um modo de falar único, mas uma família histórica de modos de falar afins e interdependentes, e os dialetos são membros desta família ou constituem famílias menores dentro da família maior.

Para as dialetólogas Ferreira e Cardoso (1994, p. 12), o conceito de dialeto não pressupõe uma hierarquização linguística, ou seja, não há uma ideia valorativa, mas de inserção de uma determinada modalidade linguística em um "sistema abstrato que é a própria língua". De tal modo, os falantes apresentam características distintas, estas, por sua vez, influenciadas por fatores extralinguísticos de ordem diversa, sejam eles diastráticos, diageracionais, diassexuais, diafásicos entre outros.

No que concerne ao desenvolvimento e ordenação dos estudos dialetais, no Brasil, a mais conhecida proposta é de Antenor Nascentes (1953), o qual propõe a delimitação de áreas dialetais por meio do confronto presença/ausência de fenômenos linguísticos observáveis, fornecendo resultados que permitem observar a realidade espacial da língua. Pensando em uma periodização dos estudos dialetológicos, Cardoso e Ferreira $(1994$, p.?) apresentam a história da dialetologia brasileira dividida nas seguintes etapas:

i) as primeira e segunda fases - caracterizadas, sobretudo, pela produção e publicação de vocabulários, glossários, dicionários e léxicos regionais, dos quais as obras O dialeto caipira (AMARAL, 1920) e O linguajar carioca (NASCENTES, 1922); ii) as terceira e quarta fases, caracterizadas, respectivamente pelo início da consolidação dos trabalhos em Geolinguística no Brasil, com a publicação do primeiro trabalho em geografia linguística realizado no Brasil - O Atlas Prévio dos Falares Baianos - APFB (1963) e ampliação do número de atlas linguísticos publicados ou em elaboração e pela incorporação de novas dimensões e fusão com outras áreas afins ao trabalho e à pesquisa dialetológica. (NEIVA, 2017, p. 84-85, grifos do autor)

Considerando-se, pois, a dialetologia e a geolinguística, vê-se a importância de ambos os ramos linguísticos para o fazer lexicográfico, uma vez que possibilitam o registro do léxico dialetal. Segundo Machado Filho: “[...] vê-se, [...] na atitude de maior aproveitamento da base de dados dos projetos de elaboração de atlas linguísticos, uma oportunidade transdisciplinar de bom termo, nomeadamente para o avanço da lexicografia moderna" (MACHADO FILHO, 2010, p. 51).

Nesse esteio, a partir de um acordo de cooperação entre a Universidade Federal da Bahia e Université Paris 13, surgiu a ideia do aproveitamento dos dados do Projeto ALiB na perspectiva dos estudos lexicográficos, o Projeto Dicionário Dialetal Brasileiro (Projeto DDB) - "obra de verve coletiva e interinstitucional que envolverá diversos especialistas, quer na área da dialetologia quer nas áreas da Lexicografia e das Ciências da Informação, do Brasil e da França”(MACHADO FILHO, 2010, p. 67), com vistas a assegurar a difusão da realidade linguística do português brasileiro no âmbito da Lexicografia.

\section{AMOSTRA DOS DADOS}

Apesar de se tratar de uma pequena amostragem diante de um universo lexical tão amplo, os resultados encontrados atestam, como era de se esperar, a riqueza das contribuições advindas de diversas línguas para a formação do léxico do português brasileiro.

\subsection{FENÔMENOS ATMOSFÉRICOS}

\subsubsection{Chuva de pedra}

Decorrente das respostas à questão 15, com a formulação: "Durante uma chuva podem cair bolinhas de gelo. Como chamam essa chuva?", esse fenômeno obteve 2 variantes: 
chuva de gelo - sf. (< chuva [este, lat. chuva de granizo - sf. $(<$ chuva [este, lat. plüvia] + de [este, lat. de] + gelo [este, lat. gelus] $]_{\sim}^{2} \rightarrow$ chuva de granizo. 'precipitação que consiste na queda de pequenos pedaços de gelo'. QSL IS: Durante uma chuva, podem cair bolinhas de gelo. Como chamam essa ahrva? plǔvia] + de [este, lat. de] + granizo [este, esp. granizo] $)^{a} \rightarrow$ chuva de gelo. 'precipitação que consiste na queda de pequenos pedaços de gelo'. QSL I5: Durante uma chuva, podem cair bolinhas de gelo. Como chamam essa chuva?

Quadro 1: Denominações para Chuva de pedra Fonte: Elaborado pelo autor

\subsubsection{Orvalho $\sim$ sereno}

No que tange às respostas à questão 20, cuja formulação: "De manhã cedo, a grama geralmente está molhada. Como chamam aquilo que molha a grama?", foram computadas 4 respostas:

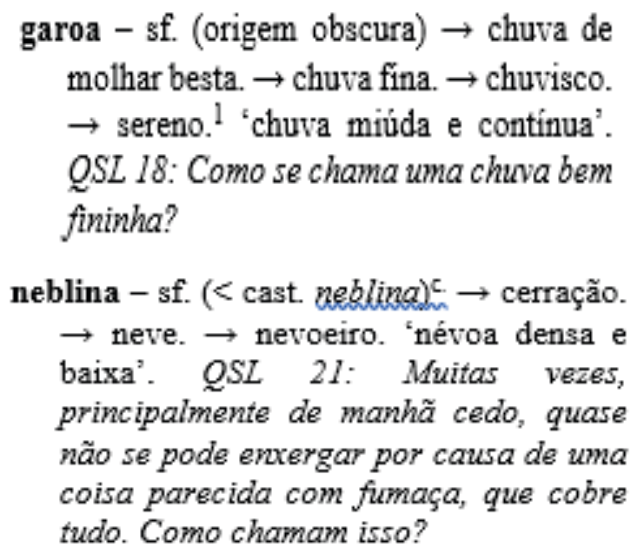

Quadro 2: Denominações para Orvalho Sereno

Fonte: Elaborado pelo autor

\subsection{ATIVIDADES AGROPASTORIS}

\subsubsection{Tangerina $\sim$ Mexerica}

Como respostas à questão 39 “[...] as frutas menores que a laranja, que se descascam com a mão, e, normalmente, deixam um cheiro na mão? Como elas são?", foram documentadas 2 formas:

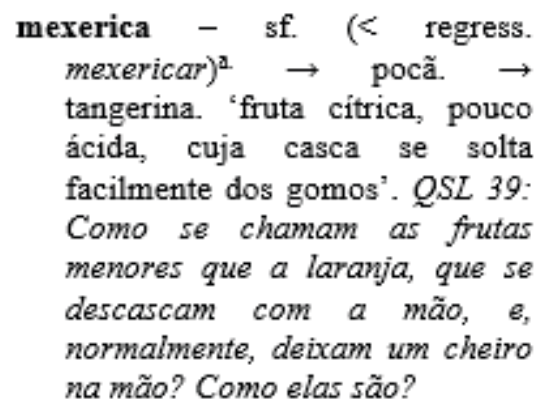


4.2.2 Mandioca $\sim$ Aipim

No tocante à questão 50 “[...] aquela raiz branca por dentro, coberta por uma casca marrom, que se cozinha para comer?”, obtiveramse como respostas as seguintes variantes:

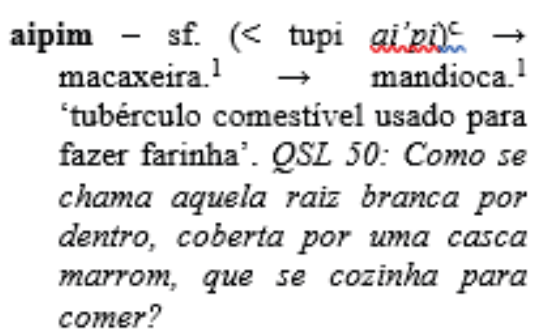

macaxeira ${ }^{1}-$ sf. (< tupi maka' šera) $)^{c}$

$\rightarrow$ aipim. $\rightarrow$ mandioca. ${ }^{1}$ 'tubérculo comestivel usado para fazer farinha'. QSL 50: Como se chama aquela raiz branca por dentro, coberta por uma casca marrom, que se cozinha para comer?

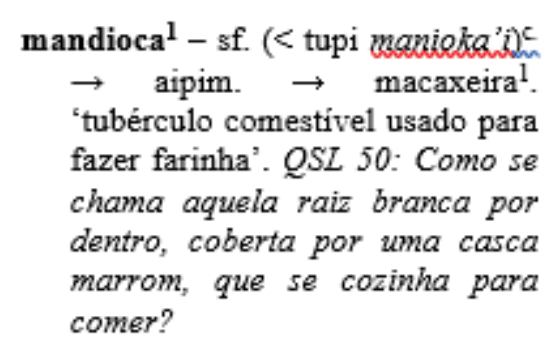

Quadro 4: Denominações para Mandioca Aipim Fonte: Elaborado pelo autor

4.3 FAUNA

4.3.1. Galinha D’Angola Guiné Cocar

Quanto à questão 67 “[...] a ave de criação parecida com a galinha, de penas pretas com pintinhas brancas?”, percebe-se mais uma vez a riqueza vocabular dos dialetos brasileiros:
capote $-\mathrm{sm}$. $(<\mathrm{fr} \text {. capot, de cape })^{\mathrm{m}}$ $\rightarrow$ galinha d'angola. $\rightarrow$ picote. $\rightarrow$ tô fraco. "ave de plumagem acinzentada com pintas brancas, originária da África'. QSL 67: Como se chama a ave de criação parecida com a galinha, de penas pretas com pintinhas brancas?

galinha d'angola - sf. $(<$ galinha [este, lat. gallina, ae] + de [este, lat. de] + angola [este, top. Angola] $)^{\mathrm{a}} \rightarrow$ capote. $\rightarrow$ picote. $\rightarrow$ tô fraco. "ave de plumagem acinzentada com pintas brancas, originária da África'. QSL 67: Como se chama a ave de criação parecida com a galinha, de penas pretas com pintinhas brancas?
picote $\sim$ picota $-\mathrm{sm} .(<\text { pico }+ \text {-ote })^{\mathrm{a}}$ $\rightarrow$ capote. $\rightarrow$ galinha d'angola. $\rightarrow$ tô fraco. 'ave de plumagem acinzentada com pintas brancas, originária da África'. QSL 67: Como se chama a ave de criação parecida com a galinha, de penas pretas com pintinhas brancas?

tô fraco $-\mathrm{sm}$. (< tô + fraco [este, lat. flaccus] $)^{\mathrm{a}} \rightarrow$ capote. $\rightarrow$ galinha d'angola. $\rightarrow$ picote. 'ave de plumagem acinzentada com pintas brancas, originária da África'. QSL 67: Como se chama $a$ ave de criação parecida com $a$ galinha, de penas pretas com pintinhas brancas?

Quadro 5: Denominações para Galinha D’Angola Guiné Cocar

Fonte: Elaborado pelo autor 
4.3.2 Libélula

Foram 5 as variantes apuradas nas respostas à questão 85 "[...] o inseto de corpo comprido e fino, com quatro asas bem transparentes, que voa e bate a parte traseira nas águas?"

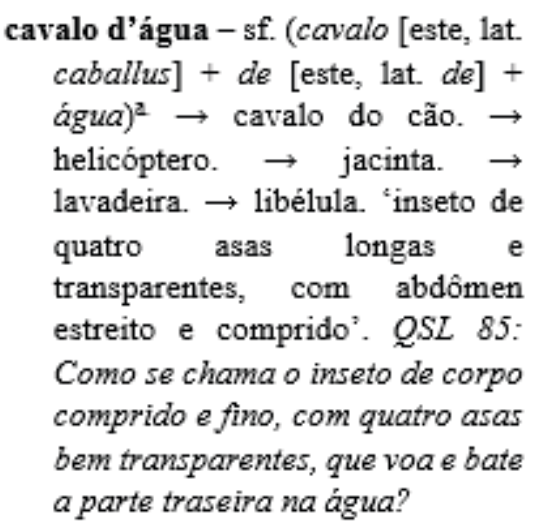

cavalo do cão - sf. (cavalo [este, lat. caballus $]+$ do [este, lat. de $+o]+$ cão [este, lat. cane $(m)])^{\mathrm{a}} \rightarrow$ cavalo d'água. $\rightarrow$ helicóptero. $\rightarrow$ jacinta. $\rightarrow$ lavadeira. $\rightarrow$ libélula. 'inseto de quatro asas longas e transparentes, com abdômen estreito e comprido'. QSL 85: Como se chama o inseto de corpo comprido e fino, com quatro asas bem transparentes, que voa e bate a parte traseira na água?
lavadeira - sf. (< lava(r) + -eira) $\rightarrow$ cavalo d'água. $\rightarrow$ cavalo do cão. $\rightarrow$ helicóptero. $\rightarrow$ jacinta. $\rightarrow$ libélula. 'inseto de quatro asas longas e transparentes, com abdômen estreito e comprido'. QSL 85: Como se chama o inseto de corpo comprido e fino, com quatro asas bem transparentes, que voa e bate a parte traseira na água?

libélula - sf. $(<\text { fr. libellule })^{\mathrm{a}} \rightarrow$ cavalo d'água. $\rightarrow$ cavalo do cão. $\rightarrow$ helicóptero. $\rightarrow$ jacinta. $\rightarrow$ lavadeira. 'inseto de quatro asas longas e transparentes, com abdômen estreito e comprido'. QSL 85: Como se chama o inseto de corpo comprido e fino, com quatro asas bem transparentes, que voa e bate a parte traseira na água?

Quadro 6: Denominações para Libélula

Fonte: Elaborado pelo autor jacinta - sf. $(<\text { fr. jacinthe })^{c} \rightarrow$ cavalo d'água. $\rightarrow$ cavalo do cão. $\rightarrow$ helicóptero. $\rightarrow$ lavadeira. $\rightarrow$ libélula. 'inseto de quatro asas longas e transparentes, com abdômen estreito e comprido'. QSL 85: Como se chama o inseto de corpo comprido e fino, com quatro asas bem transparentes, que voa e bate a parte traseira na água?

\subsection{CICLOS DA VIDA}

No tocante à questão 132, "Criança pequenininha, a gente diz que é bebê. E quando ela tem de 5 a 10 anos, do sexo masculino?", foram obtidas como respostas 6 variantes: curumim, garoto, guri, menino, moleque, pirralho.

curumim - sm. (< tupi kuru' mí) $)^{\mathrm{a}} \rightarrow$ curumim. $\rightarrow$ garoto. $\rightarrow$ guri. $\rightarrow$ menino. $\rightarrow$ moleque. $\rightarrow$ pirralho. $\rightarrow$ rapaizinho. 'criança do sexo masculino'. QSL 132: Criança pequenininha, a gente diz que é bebê. $E$ quando ela tem de 5 a 10 anos, do sexo masculino?

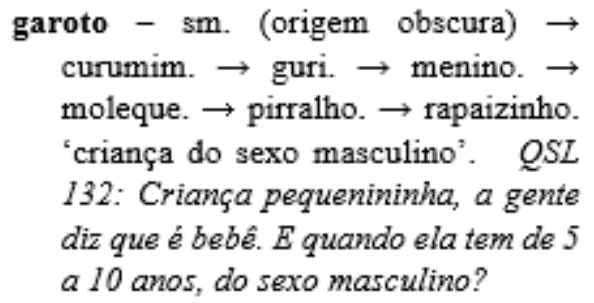




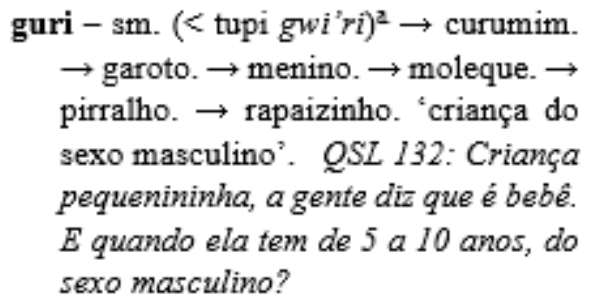

moleque - sm. (quimb. muleke) ${ }^{\mathrm{a}} \rightarrow$ curumim. $\rightarrow$ garoto. $\rightarrow$ guri. $\rightarrow$ menino. $\rightarrow$ pirralho. $\rightarrow$ rapaizinho. 'criança do sexo masculino'. QSL 132: Criança pequenininha, a gente diz que é bebê. E quando ela tem de 5 a 10 anos, do sexo masculino?

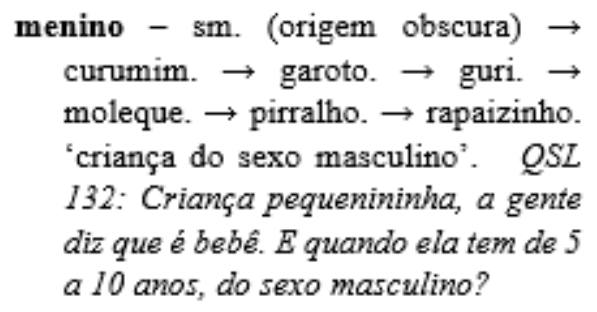

Quadro 6: Denominações para Menino

Fonte: Elaborado pelo autor

\subsection{VESTUÁRIO E ACESSÓRIOS}

\subsubsection{Ruge}

As variantes apuradas nas respostas à questão 191 "[...] aquilo que as mulheres passam no rosto, nas bochechas, para ficarem mais rosadas?" foram as seguintes:

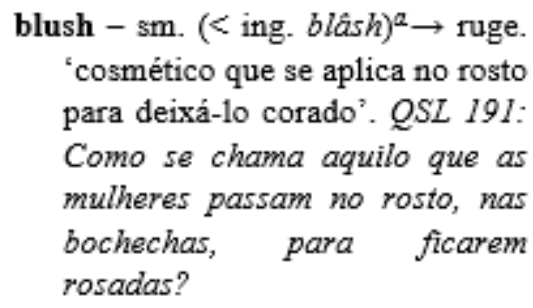

Quadro 7: Denominações para Ruge

Fonte: Elaborado pelo autor

\section{CONSIDERAÇÕES FINAIS}

Ao usar o léxico, o falante permite expressar suas ideias, as de sua geração, as da comunidade a que pertence. É no léxico, portanto, que se tem o retrato de seu tempo, atuando, inclusive como agente modificador e imprimindo marcas geradas pelas novas situações com que se depara, como aponta Câmara Jr. (1985). Ou seja, o seu estudo fornece fundamentos para um melhor entendimento de realidades, crenças, tradições e costumes de uma determinada sociedade, uma vez que "[...] o estudo cuidadoso de um dado léxico conduz a inferências sobre o ambiente físico e social daqueles que o empregam" (SAPIR, 1969, p. 49).

Com a chegada dos portugueses, aliado às relações interétnicas entre os brancos e os autóctones e, posteriormente, os africanos e imigrantes, novas unidades lexicais foram acrescidas ao inventário lexical do português. Afinal, a nova realidade exigiu o uso de novas palavras para nomear as novas relações físicas, sociais e culturais próprios do contexto em terra brasilis. Obviamente, essa nova relação possibilitou as trocas linguísticas que acolheram peculiaridades léxicas a partir desse contato, como as contribuições oriundas das línguas indígenas, sobretudo do tronco linguístico tupi, e as línguas africanas, em maior volume do subgrupo linguístico bantu. Segundo Dick (2000, p. 296), "[...] o sistema lexical brasileiro registra, em sua configuração lingǘstica [sic], uma 
simbiose de estratos de comunicação, pertencentes a três grupos étnicos demarcados [...] portugueses, indígenas e africanos, convivendo no país, desde os séculos iniciais da conquista”.

Entrementes, das cerca de 1200 línguas indígenas existentes ao longo do território nacional no momento do desembarque dos exploradores de "além-mar", nenhuma outra influenciou tanto o português brasileiro quanto o tupi. Não se pode precisar com exatidão a quantidade de vocábulos herdados das línguas indígenas brasileiras, mas já é consenso entre os especialistas que as contribuições indígenas concentram-se fortemente na toponímia e nos elementos lexicais relacionadas à fauna e flora. Isso se pôde observar no trabalho com as lexias macaxeira, mandioca e aipim.

No que concerne às contribuições das línguas africanas para composição do inventário lexical do PB, das cerca de 120 línguas que chegaram ao Brasil, observa-se uma maior contribuição das línguas do subgrupo bantu - quimbundo, umbundo e quicongo -. Tal situação explica-se devido ao contingente demográfico de escravizados falantes desse subgrupo ser maior aos outros que aqui desembarcaram. Cabe salientar que essa relação étnico-linguística manteve-se no Brasil durante todo o funcionamento da empresa escravocrata. De acordo com Margarida Petter (2007, p. 86):

\footnotetext{
A presença africana no léxico éa mais forte evidência do contato linguístico e cultural. Apontada pelos primeiros estudiosos como traço particular ao PB, como brasileirismo, merece ser avaliada com cuidado, para que não se simplifique sua extensão. Embora o desenvolvimento das pesquisas tenha aumentado o inventário dos termos considerados de origem africana, africanismos - passando de mais de 300 (MENDONÇA, 1933 e RAIMUNDO, 1933), a 1500 (FERREIRA, 1986) e atingindo 2500 (SCHNEIDER, 1991) - deve-se reconhecer que os termos de origem indígena presentes no PB são em número bem superior.
}

Ademais das contribuições das línguas autóctones e africanas, é necessária a compreensão do processo migratório para o Brasil das línguas europeias e asiáticas e seus impactos no que tange ao cenário linguístico nacional, já marcado por uma acentuada pluralidade.

Sabe-se que as línguas de migração se concentraram em regiões previamente estabelecidas, sobretudo no eixo Sul-Sudeste, principalmente por conta das questões climáticas mais favoráveis aos recém-chegados. Entretanto, tal contexto não invalida a expansão nacional dos elementos linguísticos, a depender do grau de prestigio que detivesse a língua, afinal: "Diferentes grupos em uma comunidade podem atribuir valores diversos às identidades ligadas aos falantes de outras línguas. Então os valores associados a um estrangeirismo podem muitas vezes ser conflitantes dentro da comunidade que faz o empréstimo." (GARCEZ; ZILLES, 2012, p. 15).

É certo que, em maior ou menor grau, as línguas autóctones, africanas e de imigração deixaram suas marcas no português brasileiro, não somente por transmissão direta, mas também, indireta, por via dos empréstimos linguísticos em situações de intercâmbio.

\section{REFERÊNCIAS}

ANDERSON, B. Comunidades imaginadas: reflexões sobre a origem e a difusão do nacionalismo. São Paulo: Companhia das Letras, 2008.

BIDERMAN, M. T. de C. Fundamentos da Lexicologia. In: BIDERMAN, M. T. de C. Teoria linguística. 2 ed. São Paulo: Martins Fontes, 2001.p. 95-213.

BRASIL. Decreto no 30.643, de 20 de março de 1952. Institui o Centro de Pesquisas da Casa de Rui Barbosa e dispõe sobre o seu funcionamento. Coleção de Leis do Brasil, v. 2, p. 170, 1952.

CÂMARA JUNIOR, J. M. Estrutura da língua portuguesa. 15. ed. Petrópolis: Vozes, 1985. 
CARDOSO, S. A. Geolinguística: tradição e modernidade. São Paulo: Parábola Editorial, 2010.

CARDOSO, S.. Reflexões sobre a Dialectologia. In: ISQUERDO, A. N. (org.). Estudos geolingüísticos e dialetais sobre o português. Campo Grande: Editora UFMS, 2008, p. 13-31.

COMITÊ NACIONAL DO PROJETO ALiB: Atlas Lingüistico do Brasil. Questionários. Londrina: UEL, 2001.

COSERIU, E. Sentido y tareas de la dialectología. Mexico: Instituto de Investigaciones Filológicas; Centro de Linguistica Hispanica, 1982. (Cadernos de Lingüística, n. 8)

DICK, M. V. de P. A. Inter-relação léxico e cultura na América Indígena. Estudo de Caso. Acta Semiótica et Lingüística (SBPL), São Paulo, v.8, p. 95-308, 2000.

FARACO, C. A. História sociopolítica da língua portuguesa. São Paulo: Parábola Editorial, 2016.

FERREIRA, C.; CARDOSO, S. A dialetologia no Brasil. São Paulo: Contexto, 1994.

GARCEZ, P.; ZILLES, A. M. Estrangeirismos. In: FARACO, C. A (org.). Estrangeirismos: guerra em torno da língua. São Paulo: Parábola, 2002.p. 15-36.

LUCCHESI, D. História do contato entre línguas no Brasil. In: LUCCHESI, D.; BAXTER, A.; RIBEIRO, I. (org.). O português afrobrasileiro. Salvador: EDUFBA, 2009.

LUCCHESI, D. Norma linguística e realidade social. In: BAGNO, M. (org.). Linguística da norma. São Paulo: Edições Loyola, 2004. p. 63-92.

MACHADO FILHO, A. V. L. D. Um ponto de intersecção para a dialetologia e a lexicografia: a proposição de elaboração de um dicionário dialetal brasileiro com base nos dados do ALiB, Estudos Linguísticos e Literários, n. 41, p. 49-70, 2010.

MATTOS E SILVA, R. V. Ensaios para uma sócio-história do português brasileiro. São Paulo: Parábola Editorial, 2004.

NEIVA, I. Vocabulário Dialetal Baiano. 2017. 270 f. Tese (Doutorado) - Programa de Pós-Graduação em Língua e Cultura, Universidade Federal da Bahia, Salvador, 2017.

PETTER, M. Línguas africanas no Brasil. África: Revista do Centro de Estudos Africanos. USP, S. Paulo, v.27-28, p. 63-89, 2006/2007. PIEL, J. M. Origens e estruturação histórica do léxico português. In: CASTRO, I. et al. Curso de história da língua portuguesa: leituras complementares. Lisboa: Universidade Aberta, 1991. p. 233-242.

RAZKY, A.; SANCHES, R. D. Variação do item lexical “prostituta” no projeto atlas lingüístico do Amapá. Linguasagem, São Carlos, v. 23, 2015 . 
RODRIGUES, A. As outras línguas da colonização do Brasil. In: CARDOSO, S. A.; MOTA, J. A.; MATOS E SILVA, R. V. (org.). Quinhentos anos de história linguística do Brasil. Salvador: Secretaria da Cultura e do Turismo da Bahia, 2006. p. 148-150.

SAPIR, E. Linguística como ciência. Rio de Janeiro: Editora Livraria Acadêmica, 1969.

() (1) $\circledast \circledast$ 